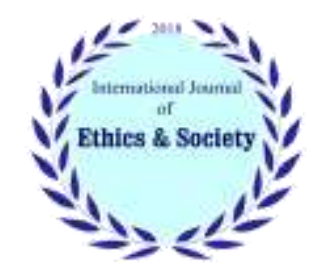

International Journal of Ethics \& Society (IJES)

Journal homepage: $\underline{\text { www.ijethics.com }}$

Vol. 3, No. 2(2021)

\title{
Morphology of the Religious-Moral Ideas of A. J. Ayer \& the Influence of Russell \& Early Wittgenstein on Him
}

\author{
Mohsen Shiravand \\ Dept. of Islamic Studies, Faculty of Theology, University of Isfahan, Isfahan, Iran
}

\section{Abstract}

Background: No doubt, A. J. Ayer is one of the contemporary philosophers who has unorthodox ideas in the domain of religion and ethics. In the domain of epistemology, Ayer believed that failure of "analysis" or "empirical proof" will lead to the meaninglessness of the proposition. Thus conceived, theological propositions are nonsensical while moral propositions are mere expression of feelings and then both of them are considered to be meaningless.

Conclusion: The author believes that a major part of the ideas of Ayer is derived from such analytic philosophers as Russell and Early Wittgenstein. The objective of the present essay is the demonstration of the latter claim through the study and explication of the religious and moral ideas of Ayer. This essay is written based on the method of documentation and analysis. Among the results of this essay, one can refer to the demonstration of the deep influence of Russell and Early Wittgenstein on the religious and moral ideas of A. J. Ayer.

Keywords: Ayer, Russell, Early Wittgenstein, Ethics, Religion.

\section{Introduction}

The thoughts of Sir Alfred Jules Ayer (1910-1989) are among the most well-known and at the same time most significant ones that have emerged in the history of human thought in the field of religion and ethics. This contemporary Anglophone linguistic philosopher has considered the millennial religious doctrines to be nonsense and meaningless.
Moreover, according to Ayer, moral propositions are nothing more than mere expression of human emotions and feelings and thus, this group of human knowledge is also described as meaningless. There is no doubt that numerous studies have been conducted so far regarding Ayer's thought and principles and discussed his ideas in two domains

* Corresponding Author: Email: m.shiravand23@gmail.com

Received: 13 Mar 2021

Accepted: 12 May 2021

6

Available at: www.ijethics.com 
of religion and ethics. Then, this essay is not to provide a new study as to these issues. Rather the present essay is devoted to one of the less appreciated domains in Ayer scholarship, i.e. the influence of Russell and Early Wittgenstein on Ayer (in this essay, wherever we discuss Wittgenstein, we are referring to Early Wittgenstein). The author believes that the thoughts of Ayer in two domains of religion and ethics are hugely influenced by Russell and Early Wittgenstein. Even in the methodological domain, Ayer is considerably influenced by these two philosophers. The goal of the present study is to prove this claim.

This essay which has been authored based on a descriptive-analytic method, answers the following question:

"What is Ayer's perspective of religious and moral propositions and to which extent his ideas in these two domains are influenced by the ideas and thoughts of Russell and Early Wittgenstein?”

This essay is composed of three parts: first part studies the key ideas and epistemological principles of Russell, second part is focused on the ideas of the Early Wittgenstein and the third part discusses the influences of the aforementioned philosophers on Ayer's ideas in two domains of religious and moral propositions. The essay is concluded with the presentation of the results.

\section{Sir Bertrand Russell}

Empiricism and Elimination of Metaphysics: Two stages can be identified in the intellectual life of Bertrand Russell (1872-1970): in the first period, he was completely under the influence of mathematics and had a Platonic position. In this period, he believed in universals. Thus, he held that there are universals beyond the world of experience that can be perceived in an immediate way and have their special existence and are independent from objects and ideas. (1) In those times, he considered philosophy to be a syllogistic science that is partially independent from sensory experience. In the second period, he became an empiricist philosopher and turned to positivism. In this period, the problem of "universals" seemed to him to be baseless and every metaphysics was meaningless in his eyes.
(2) The philosophy was no longer a syllogistic science for him rather it was deemed to be conditional upon experience in its English sense. Even in mathematics, he does not observe any Platonic beauty, rather mathematics is considered to be simple practical tool of science. In this stage, Russell is almost a classic scientist: he argues that only the method of natural sciences can be seen as the means and vehicle of knowledge. He believes that human perfection resides in technic and the development resulted from it. His realism is very close to the ideas of Hume and an unconditional skepticism - which is one of the consequences of empiricism - heavily overshadows his whole thought. Russell in philosophy is under the influence of Moore. He believes that philosophy must be a science that acquires its problems from the natural sciences not from religion and ethics. Accordingly, Russell suggests that every type of mysticism and metaphysics in general must be left out of the domain of philosophical discussions. For he is an empiricist and introduces philosophy as the maiden of empirical science (3). He believes that only by the natural sciences, we can reach the reality of course not by the language of determinacy rather by the language of probability. It is seen that Russell is also under the influence of the empiricist tradition. Here we outline the ideas that have hugely influenced Ayer.

Logical Atomism; Truth and Falsity of Propositions:

The belief in Logical Atomism is considered to be one of the fundamental ideas of Russell. This theory has also influenced the logical positivists. Logical Atomism has a complicated history and is rooted in two of Russell's works, i.e. "Philosophy of Logical Atomism" (1918) and "Logical Atomism" (1924), as well as the conversations of Russell and Early Wittgenstein Between 1912-1913. In this theory, Russell introduces the world to be composed of the sense data which are logically interconnected. (4) In Bochenski's words, this is a type of empirical pluralism that Russell joint it as a result of the mathematical studies and his research on Leibniz's opus. It is needless to say that the theory of pluralism in the domain of epistemology results in significant philosophical consequences (3). Russell believes that although matter is real, it is not directly 
available to human knowledge. Russell's present idea is seemingly under the influence of the doctrines of George Edward Moore because he believes that only the sense data represent the locus of human knowledge. Thus, table's color and solidity despite their being regarded as real affairs are by no means the "properties of table". This is itself proven in this way that different individuals sense various sense data. The space where the sense data are found in it varies depending on the sense that accepts them and a fortiori, based on the person who receives them. It is clear that Russell's present idea is under the influence of empiricism. Empiricism itself has given rise to the empirical pluralism. The significant point that should be taken into account and has also influenced Ayer is the impact of the idea of Logical Atomism on language. According to Russell, since the world is constituted of the tiny logical particles, then one can analyze the language like the physical objects into tiny particles. If we manage to minimize the language in a way that we could reach the unanalyzable particles, the tiniest particles that remain are called "logical atoms". He contends that if these linguistic logical atoms are speculated, they can uncover the hidden assumptions in sentences and in this way determine its truth or falsity. For example, "The King of America is Bald", this simple sentence can be analyzed into three logical atoms:

1. There is a king in America.

2. There is just one king in America.

3. The King of America does not have any hair. Since we know that there is no king in America, then the first sentence is false. Therefore, the sentence "The King of America is Bald" is wrong. But this point does not wholly prove the falsity of the sentence. Since the counter-sentence of it, i.e. "The King of America has a head full of hairs", is also false. In both sentences, it is assumed that America has a king.

Anyway, Russell believes that by linguistic logical atomism - which is itself influenced by empiricism - one can evaluate the validity and degrees of the truth of the propositions.

\section{Theory of Descriptions:}

The most important contribution of Russell in the domain of linguistics was the presentation of the theory of "descriptions". In this theory, Russell holds that the truths cannot be expressed by the everyday language. For everyday language has numerous deficiencies and ambiguities. He believes that if philosophy wants to make itself immune to error it should keep away from everyday language and instead use a language that is established based on the mathematical logic and is more like a branch of mathematical functions. According to the theory of descriptions, to analyze a "name" we need to use expressions or words that are dependent upon a particular individual object. Russell holds that the sentence that contains decisive descriptions is indeed a shortcut for expression of a series of the themes through a chain of propositions. (5) In this way, Russell succeeded to show that grammar blurs the logical form of the sentence. For example, in the sentence "The King of America is Bald" the subject does not exist or is ambiguous (6). It is needless to say that this theory has also considered the truths in the world to be restricted to mere experience and matter and left the metaphysical affairs out of the external world under the influence of the empirical methodology. Moreover, language can merely deal with the representation of the empirical affairs.

Russell and the Explanation of Wittgenstein's Logical Atomism:

Russell is an interpreter of Wittgenstein's theory. (The present essay will explain Wittgenstein's logical atomist in full details). To explain this theory, Russell expressed several premises that are of paramount importance:

1- If a statement is to be meaningful, it should be united with the objective reality. Otherwise the sentence "Victor came" will give nothing to us. Then, there should be a share point between the word and the meaning. In other words, there should be something in common between the expression "Victor came" and Victor's coming.

2- The union relationship cannot be pronounced. The relationship between the word and the meaning is not pronounceable. What is pronounced is just the words and voices and the relationship between the voice and the referent is not uttered. 
It is needless to say that some objections can be raised against this argument. If there is to be a relationship between the word and the meaning, there will be an infinite regress. Both a regress in language and a regress in mind. For example, if it is said that "I am thirsty and I want water", here there is a relationship between the water and the fluent object and if we want to pronounce this relationship, we will face a regress. If it is supposed to be pronounced, this would be deemed in the mind. When the relationship is pronounced, there will be no relationship, because by pronunciation the relative property disappears. (7) If man wants to pronounce a word in order to express its meaning, he will never be able to pronounce the relationship between them. The father/son relationship is an example of this kind. To conceive such a relationship, one needs to deem first a father and a son, but as soon as he thinks of the relationship between the father and the son, this relationship will disappear. (7) Russell is a neorealist. Neorealists despite their diversity, have several common properties that consist of:

1. They all believe that they can have a direct access to the reality and understand it.

2. They are all empiricist. In other words, their intellectual paradigm is scientism.

3. Their methodology is emphasis on the details and their approach to the problems is "selective and case based". Thus, it is not logical to expect them to build a well-established system and they are not after such a plan. Russell's main idea is the theory of "reductive analysis". It was based on this idea that he pursued the theory of descriptions. As to the theory of reductive analysis, there is no difference between mathematics and logic and these two are essentially one. It seems that the denial of dualism between the body and mind is also influenced by this very theory. (8)

According to Russell, since such expressions as "Gold Mountain" do not have a determinate meaning and are not a name that would refer to a creature, then they can be just "descriptions". In fact, it is this strategic idea that led Russell to another principle. This principle was distinguishing "formal and logical structure or form" from the "grammatical structure or form". This distinction is of a paramount importance. For it leads to the elimination of metaphysics from the domain of philosophy. Russell believes that a sentence in ordinary language may be correct in view of grammar, but if it is presented in "logical" form, we would be no longer able to call it a "proposition" with meaning that could be true or false. For these are just the case with the logical structure not with the grammatical structure. The conclusion that can be drawn from this issue is that every sentence which is known through analysis to lack a logical structure should be left out of the domain of philosophy. In fact, the elimination of metaphysics and the like, is done given the un analyzability of this type of sentences. These doctrines suggest that the only subject that can survive within the epistemic geometry of Russell and precipitate in his philosophy is the propositions attributed to modern science. Philosophical knowledge as conceived by Russell lies in the domain of empirical propositions. By his theory of logical atomism, Russell struggled to logicize the empiricism. What is acquired through this theory (the foundation of which belongs to Wittgenstein) is that on the one hand, "human thinking is logically of a propositional framework", and on the other hand, any proposition can be a proposition only when it is reporting a fact that can be experienced by all. If it is so, this proposition cannot be analyzed into simpler propositions and then it is considered to be an atomic proposition. Russell has borrowed the idea of the world's being composed of the independent atoms from Leibniz. Accordingly, he denied all types of idealism including the object and subject, and believed that every type of direct access to the matter is impossible and sense data are merely the result of human direct contact with the external world (8).

\section{Ludwig Wittgenstein}

The philosophy of Wittgenstein (1889-1951) has had a considerable role in the formation of the ideas of Ayer. His ideas are inspired by Russell's philosophy of logical atomism and depict a determinate direction in this philosophy. Wittgenstein is important from certain respects:

- He was one of the key sources of the formation and expansion of the Neopositivism of the $\mathrm{Vi}$ enna Circle and logical positivism. He was not a member of the Circle but his relationship with the Circle was through two ways, i.e. one through Schlick and Waismann and the other, through the Tractatus Logico-Philosophicus. 
- The other aspect of significance of Wittgenstein's philosophy is due to Analytical Philosophy or Linguistic Philosophy that emerged in Oxford in the third decade of Twentieth century because this school owes its basic theories to Wittgenstein (3).

As previously mentioned, we are discussing the early philosophy of Ludwig Wittgenstein. The main source of the ideas of early Wittgenstein is Tractatus Logico-Philosophicus (Logische-Philosophische Abhandlung). In Tractatus, Wittgenstein has presented his linguistic theory drawing upon Russell's theory of logical atomism. He has considered the language and the world to be composed of simple affairs among which there is a correspondence. To put it otherwise, the names that are expressed through language constitute the propositions for each one of which there is an object in the outside world. He believes that there is something in common between the language and the world and it is due to this common affair that the language is a representation of the reality. This is to say that Early Wittgenstein believes that the world is analyzed into the facts. It is needless to say that facts refer to something other than the things. The language is a representation and picture of these very facts. According to Wittgenstein, there is a relationship between the mental form and the fact through the logical relation between the objects. Therefore, proposition is a picture of the fact that is represented through the language and the difference of the propositions lies in the difference of the facts (9). He has outlined his philosophy through seven major propositions as follows:

1. Die Welt ist alles, was der fall ist (The world is everything that is the case).

2. Was der Fall ist, die Tatsache, ist das Bestehen von Sachverhalten (What is the case, the fact, is the existence of atomic facts).

3. Das logische Bild der Tatsache ist der Gedanke (The logical picture of the facts is the thought).

4. Der Gedanke ist der sinnvolle Satz. (The thought is the significant proposition).

5. Der Satz ist eine Wabrheitsfunktion der Elementarsätze.(Der Elementarsatz ist eine Wahrheitsfunktion seiner selbst.) (Propositions are truth-functions of elementary propositions
(An elementary proposition is a truth-function of itself).

6. Die allgemeine Form der Wabrheitsfunktion ist. $[\overline{\mathrm{P}}, \bar{\xi}$, $\mathrm{N}(\stackrel{\bar{\xi}}{\bar{\xi}})]$. Dies ist die allgemeine Form des Satzes. (The general form of truth-function is: $[\overline{\mathrm{P}}, \bar{\xi}, \mathrm{N}($ $\bar{\xi})]$. This is the general form of proposition.

7. Wovon man nicht sprechen kann, darüber muß man schweigen (Whereof one cannot speak, thereof one must be silent).

These seven propositions form the general principles of the thought of Early Wittgenstein. The key idea of logical atomism is that the basis of the meaning of our sentences is the a priori relationship between the simple expressions and their simple equivalents in the world, i.e. logical atoms. In a completely logical language, atomic sentences are descriptions of the forms of these atoms and the complex sentences are combinations of these atomic sentences. However, the sentences of the ordinary language would have a misleading appearance (10). By the study of Wittgenstein's logical atomism and the heptafold propositions, we can see the domination of empiricism and the elimination of metaphysics and theological affairs in the domain of world and language. The world is consisted of matter and experience. The proposition is a mere representation of the world and only has the capability of reflection of the matter and experience.

Picture Theory of Language:

Wittgenstein believed that if the language is to be able to represent the reality and the sentences are to stand for the state of affairs, there should be something shared by the sentence and the state of affair. One can state that the sentence is like a picture of the possible fact. The sentences are impossible to have a meaning unless the language reflects the reality like a mirror. The concept of meaning in the picture theory of language is more concerned with the common logical structure shared by the wellformed proposition whose referent is in the outside world. The proposition that does not have any referent will have no picture. The proposition that lacks a picture does not have any meaning. Thus conceived, the language has an essence and is in charge of the representation of the common structure between the well-formed proposition and its 
referent in the outside world. Moreover, here there is a sheer line between the meaningful propositions and the meaningless propositions. In fact, the use of language does not have any role to play in the evolution of the meanings and the meaningful propositions. It is not important that how the words are used in which context rather what is of importance is the isomorphism of the propositions and their referents in the outside world from the perspective of the metaphysical subject. According to Wittgenstein, the world exists for us as far as it is describable; in other words, as far as we can speak of the states of affairs in the world in a meaningful way. In Tractatus, Wittgenstein notes that the borders of the language determine the borders of the world. In one of the renowned propositions of the Tractatus, Wittgenstein states: "What cannot be shown, cannot be said" (9). A simple proposition contains something as far as it pictures the reality. Accordingly, Wittgenstein believes that there is a relationship of identity between the language and the world and the propositions that represent the world reveal the states of affairs in the world. Then, the logic of propositions is the very logic of the world (11). It is needless to say that in this theory there is a radical form of empiricism. In the domain of ontology, the world is just the matter and there is no occasion for the metaphysics. In the domain of linguistics, the language is a mere report of the material world. Truth and falsity are also limited to the external world. In the section of Ayer, we will see that these ideas in the domains of religion and ethics have hugely influenced Ayer.

Comparison of Russell's Logical Atomism and Wittgensteinian Doctrine:

Wittgenstein's doctrines in Tractatus Logico-Philosophicus is an echo of Russell's theory of logical atomism that influenced the logical positivists and other followers of the linguistic analysis in this era. When we compare Wittgenstein's Tractatus with the Philosophy of Logical Atomism, we find out clear similarities. In fact, the first half of the Tractatus in which a type of metaphysical system is developed can be considered as an example of logical atomism. Generally speaking, the doctrines of Tractatus include "Picture Theory" and "Theory of
Truth-functions". But before turning to these theories that have had a key role in the emergence of the ideas after them particularly the thoughts of Vienna Circle, we need to outline a set of points as to Wittgenstein's logical atomism. According to Wittgenstein, there is a logical unity between the mind, world and language. Moreover, from an epistemological point of view, the domain of human knowledge is limited to the domain of the positive experience. This Wittgensteinian doctrine in practice leads to the denial of metaphysics and the supersensory affairs. At the beginning of Tractatus, the world is considered to be the totality of the facts. It is clear that "fact" lies in the domain of positive experience and it is essentially available to public experience. According to Wittgenstein, thinking is always associated with the "logical relation". To put it otherwise, world is the totality of propositions (world is a logical whole that just has a propositional nature) and man always thinks in "propositional" way. Wittgenstein struggles to lead this idea to its final fruition by his "picture theory of language". This theory suggests that there is a correspondence between human mind that is a propositional affair and the facts that represent the particles of the world. In fact, human mind is a picture of the objective world and this means that there is an identity relationship between the mind and the world. Therefore, firstly, the world is consisted of a series of the facts that are independent from each other. Secondly, knowledge consists of the picture of the facts; thirdly, logic is merely of identity property and does not refer to the factual world; fourthly, the world is of a nature that can be just examined by the empirical sciences (8). As to the logical atomism, it needs to be mentioned that Wittgenstein suggests that only propositions have a meaning and are either true or false. On the other hand, names have referents and do not have any meaning. Name gives meaning to the same thing to which it refers. Wittgenstein's picture theory actually suggests that the reality becomes connected with the language through the propositions that picture the realities. One of the differences of Russell's logical atomism and that of Early Wittgenstein is that although these two thinkers considered the propositions of the perfect language to be correspondent with the facts, 
Wittgenstein believed in just one type of language and in one level; because according to Tractatus, language consists of fundamental propositions and the truth-functions of the fundamental propositions. The fundamental propositions are a picture of the state of the outside world and the fact consists of the state of affairs and objects. However, according to Russell, language is not of one level and there is a hierarchy of languages. Russell's theory of the hierarchy of languages is influenced by his theory of types which had been developed for solving its paradoxes. According to Russell, the most superficial level of language is the one that Wittgenstein introduces as the only possible language in his Tractatus Logico-Philosophicus. Russell calls this object-language. In object-language, there is one by one correspondence between the most fundamental parts of the language the reality. According to Russell, in this level of language, one cannot speak of something other than the facts (e.g. the language itself) and enumerate its properties and if we want to express the features of this level of language, we should speak of a higher level language. It should be also added that in Tractatus, Wittgenstein has announced that the meaning of a word is the object to which the word refers: "A name refers to an object. The object is the meaning of that name" (9). He believes that a meaning for being a meaning should not be just consisted of one or several referents rather it should be determinate too. In fact, meaning is the determinate referent. This is why he states, "a proposition has one and just one perfect analysis" (9). If the meaning is the determinate referent, then one should draw two conclusions of language and the world based on it: A) Every meaningful language should be finally analyzed into the fundamental propositions (9). Moreover, simple proposition is a concatenation of names (9) and names in this context refers to the specific names of the simple objects.

B) In final analysis, the world should reach to the "simple objects". In fact, there should be such simple objects that language can represent them. This is why he believed that "objects make the world's substance' (9). According to Early Wittgenstein, meaningfulness of language is hinged upon its testability. For this reason, the language of the empirical science was accepted as the standard language and other languages (i.e. logical, philosophical, religious, mystical, moral and artistic propositions) were evaluated and examined as compared to this language and its specific features (12).

Criticism of Logical Atomism:

Objection 1: The most important problem of the logical atomism is that it reduced the task of philosophy into the mere analysis of the words used in the philosophical issues while this is the reduction of metaphysical problems into linguistic issues.

Objection 2: Having developed the "picture theory of language", Russell and Wittgenstein take it for granted that the parts of language are correspondent with the parts of the world. Thus, they are struggling to discover the world's parts and know the universe through the exploration of the parts of language while this presupposition, if not incorrect, at least requires to be demonstrated.

Objection 3: If we neglect the two previous objections and assume that there are atomic truths in the factual world which are correspondent with the linguistic atoms. It should still be asked that upon which reason has Russell restricted the atoms of the factual world to the sensory objects and their properties? Whether the sentences "God is Omniscient" or "My soul is capable" cannot be an atomic sentence? In other words, the philosophy of logical atomism has an unwritten presupposition which is also hundred percent wrong that reads: "All creatures are sensible". At least, it should be said that this philosophy not only fails to explain the supersensible entities rather it is not at all concerned with them and neglects their ontological explication.

\section{A. J. Ayer \\ Division of Propositions as the Lever of Elim- ination of Theology and Ethics:}

The most fundamental thoughts of Ayer have been presented in "Language, Truth and Logic" in a compact fashion. This work is the manifest of the Vienna Circle in the domain of religion and ethics. The author believes that the main framework of this work and other works by the Ayer is grounded in the ideas and thoughts of Russell and Early Witt- 
genstein. Ayer is the philosopher of the age of "linguistic analysis and the analysis of propositions". Then, it is totally natural that he accepts the essential factors of the analytic philosophers. No doubt, the intellectual framework of Ayer is constituted of the epistemology of propositions. Acceptance of this epistemology (division of the proposition into a priori and a posteriori) and Ayer's specific notion of it provides a lever for elimination of the metaphysical and moral propositions. For this reason, this discussion will be the point of departure of our analysis of Ayer.

\section{Typology of Propositions: A Priori vs. A Pos-} teriori:

Ayer has set the very foundation of his main work on the division of the propositions into "Analytic" and "Synthetic" (13). We do not need any argument to state that Ayer considered himself in the domain methodology to be an empiricist and shared the ideas of Vienna Circle and Hume. Ayer believes that knowledge is secured on the experience. Drawing upon Hume and the ideas of Russell and Wittgenstein, he suggests that something can be called a proposition that either represents the relations between the notions or expresses the facts. The first group includes the a priori propositions of logic and pure mathematics. These propositions do not represent the outside world, then they cannot be refuted by the experience. These propositions are analytic and then, they are necessary. The second group hosts the propositions that are concerned with the experience and have a probable state. In other words, they cannot be decisive. Ayer believes that the verification of the propositions by the sense and experience is the only way of meaningfulness of propositions. If a proposition fails to be tested with this criterion while it is not a tautology, it will be metaphysical. Since the metaphysical propositions are neither true nor false, then they are meaningless (13). It should not be neglected that the main source of Ayer's ideas is the Vienna Circle and the Cambridge philosophers like Russell and Wittgenstein. Although Russell's thought dominated the intellectual space of Ayer, his main theory in "Language, Truth and Logic" - i.e. the announcement of the meaninglessness of the metaphysical propositions based on the division of the propositions into a priori and a posteriori - is grounded in Wittgenstein's Tractatus.

'From Wittgenstein's Tractatus, I learned that the meaningful propositions are of two types: they are either tautological like the propositions of logic and mathematics or can be proven through an empirical method. Every other thing including metaphysics and theology is meaningless in its precise sense" (14).

Here we can easily see the footprints of Russell and Wittgenstein within the main framework of Ayer's epistemology. Elimination of the metaphysical propositions and meaninglessness of the moral propositions occur based on the acceptance of the division of propositions. This is an issue that had its origin in the thoughts of Russell and Wittgenstein. Religious and Mystical Propositions:

As it was seen, Russell and Wittgenstein considered the metaphysical propositions to be nonsensical and meaningless. Drawing upon Russell and Wittgenstein, Ayer developed the most radical and explicit version of this doctrine in his philosophy. Religion and its metaphysical propositions are considered by Ayer to be nonsensical and meaningless. God, paradise, hell and soul are regarded as baseless and vacuous. According to Ayer, the existence of God can neither be demonstrated through experience nor through analysis in a tautological manner (15). Ayer believes that if a theist has a personal experience of God and considers it to be evidence can prove God, this will never substantiate the existence of God. Accordingly, Ayer regarded the theological propositions to be meaningless and nonsensical.

"Every empirical sentence that cannot be empirically proven is nonsensical in its true sense. This is more the case with what we call metaphysics and theology" (16).

Ayer examines the metaphysical propositions of mysticism with this touchstone. He believes that knowledge is nothing but retelling and conveying it to others and since the mystic is not able to represent and convey his own knowledge, then mystical propositions are non-cognitive propositions.

"If the mystic says that he has understood certain realities but he cannot express them, this is useless. For we know that if he really knew anything he 
could have expressed it. In other words, he would have been able to prove the authenticity of his intuition via empirical method. The very fact that the mystic is not able to reveal what he knows ... shows that his state of mystical intuition cannot be considered to be a truly cognitive state" (13).

Point: The question that would come to our mind is that Wittgenstein's Tractatus that has hugely impressed Ayer is of certain mystical and religious streaks. But these mystical remarks have not influenced Ayer. The reason for this should be sought for in the following word of Wittgenstein that Ayer has cited in "Language, Truth and Logic:

"I wholeheartedly accept the following word by Wittgenstein: Wovon man nicht sprechen kann, daruber muss man schweigen! But I did not pay any attention to his following remark: "whatever cannot be said, can be shown in some way" (i.e. I didn't accept it and easily abandoned it" (14).

In fact, Ayer wants to argue that showing something that does not exist is a baseless and meaningless word even if this word is said by a man like Wittgenstein. It is needless to say that Ayer's objection is that this aphorism by Wittgenstein is not in line with the ideas of Positivists (15).

\section{Moral Propositions:}

Inspired by the doctrines of Russell and Wittgenstein, Ayer is the inventor of the theory of moral emotivism. He is neither a moral naturalist nor an intuitionist a la George Edward Moore. His main thesis is the domain of moral propositions is that ethics can be neither analyzed nor empirically verified. He believes that there is no maxim that we could use it as a touchstone to examine the validity of the propositions in which there are moral notions. Ayer believed that the unanalyzability of the moral notions has its origin in their being pseudonotions (13). He argues that the existence of a moral symbol in a proposition does not add anything to the content of the proposition. For example, if we say to someone, "By stealing that money you have done a wrong thing", we have not said anything more than "you have stolen that money" (13). He believes that adding the phrase "you have done a wrong thing" does not add anything to the action rather it is merely an expression of the individual's moral feelings and abhorrence (13). In fact,
Ayer has considered the moral words, i.e. "good and bad" to be affairs concerned with "feeling" not something real that can be proven or falsified. According to Ayer, "expression of feeling" is different from the "confirmation" of feeling and one cannot say that it is true or false. For example, think of the following that reports of one's personal experiences: "I morally feel bad that you have committed theft". This just expresses someone's personal hatred but it does not prove that there is such a feeling. Ayer believes that moral words are neither provable nor falsifiable just like the phrase "Yum yum". To put it in a nutshell, Ayer's theory of emotivism suggests that ethics is nothing but an expression of emotions and then it can be neither true nor false (15).

Shortly speaking, the gist of Ayer's doctrines in the domain of religion and ethics is grounded in empiricism, elimination of metaphysics, meaninglessness of ethics and impossibility of substantiation of truth or falsity of unempirical propositions. These are themes the building block of which has been grounded by such philosophers as Russell and Early Wittgenstein.

\section{Conclusion}

A. J. Ayer succeeded to prove himself as a student of Russell and Wittgenstein. Empiricism as the unique valid source for discovery of truth was a souvenir of positivism. This was the school that has Russell and Wittgenstein as its theoreticians. Russell and Wittgenstein were the pioneers of the theory of linguistic analysis. Elimination of metaphysics in the domain of philosophy was an achievement of Russel and Wittgenstein's theory of logical atomism. Meaninglessness of propositions that are not empirically provable and at the same time are not considered to be tautological is one of the ideas of Russell and Wittgenstein. Ayer is the product of such doctrines. In other words, Ayer is a philosopher who has derived the epistemological theses of empiricism and impossibility of truth and falsity of metaphysical (religious and moral) propositions from these two philosophers. Even though emotivism is attributed to Ayer, it 
was indeed the epistemological doctrines of Russell and Wittgenstein that played a key role in its evolution. Therefore, we can conclude that A. J. Ayer's philosophical discourse has a RussellianWittgensteinian basis and every analysis of Ayer should be informed of this key idea.

\section{Ethical Consideration}

Ethical issues (such as plagiarism, conscious satisfaction, misleading, making and or forging data, publishing or sending to two places, redundancy, etc.) have been fully considered by the writers.

\section{References}

1. Russell B (1902). The principles of mathematics. Cambridge University Press, UK.

2. Ross D, SpurrettD (2007). Notions of cause: Russell's thesis revisited. Brit. J. Pbil. Sci, 5:1-32.

3. Bochenski M (1956). Contemporary European philosophy. University of Califomia Press, USA.
4. Russell B (1918). The philosophy of logical atomism. Fontana, the Monist, 28: 495.

5. Russell B (1919). Introduction to mathematical philosophy. George Allen and Unwin, London/UK.

6. Kleinman P (2013). Philosophy Key: From Socrates and Plato to Ethics and Metaphysics. Adams Media, USA.

7. Nasri A (2006). Analyticalphilosophy and theory of cognition. Elm Publication, Iran. (In Persian).

8. Khatami M (2012). Introduction to contemporary western philosophy. Elm Publication, Iran. (In Persian).

9. Wittgenstein L (2016). Tractatus Logico-philosophicus. Chiron Academic Press, USA.

10. Popkin R, Stroll A (1972). Introduction to Pbilosophy. $2^{\text {nd }} e d$. Holt, Rinehart and Winston, New York.

11. Hanfling O (1989). Theories of meaning from reference to use. Parkinson, London.

12. Gharavi A (2006). Wittgenstein and theory of meaning. Journal of Philosophical Research, 2 (124): 112-133.

13. Ayer AJ (1936). Language, truth and logic. Dover Publication, INC, New York/USA.

14. Ayer AJ (1979). Part of my life: The memoirs of a pbilosopher. Harcourt, Brace, Jovanovich, USA.

15. Martin R (2000). On Ayer: Wadsworthphilosopher's series. $1^{\text {st }} \mathrm{ed}$. Cengage Learning, USA.

16. Ayer AJ (1984). More of my life. Collins, USA. 